\title{
HUMAN SUPERVISED VIRTUAL ORGANIZATION MANAGEMENT
}

\author{
Alexandra Augusta Pereira-Klen ${ }^{1}$, Edmilson Rampazzo Klen ${ }^{2}$ \\ GSIGMA - Intelligent Manufacturing Systems Group \\ UFSC-Federal University of Santa Catarina, Florianópolis-SC, Brazil \\ Automation and Systems Department ${ }^{1}$ \\ Production and Systems Engineering Department ${ }^{2}$ \\ klen@gsigma.ufsc.br ${ }^{1}$, erklen@gsigma.ufsc.br ${ }^{2}$
}

\begin{abstract}
This paper introduces the Virtual Organization Management (VOM) under the view that management is a liberal art. A dynamic and fluid VOM framework is proposed based on some management elements and having the Distributed Business Process (DBP) as its kernel. Then another dimension is added to the framework: the VO manager's behaviour. At the end some functionalities to support human-supervised VOM are presented.
\end{abstract}

\section{INTRODUCTION}

Management is an almost-50 years-old discipline. The Collaborative Networked Organization - where the Virtual Organization (VO) is inserted - is considered to be an emerging discipline. How to combine both in order to achieve an effective management of VOs? If this management is human-supervised and if different managers imply different management styles (even if they rely on the same management elements and on the same enablers), does this mean that there are different ways to manage a VO? And, if positive, can we personalize a VOM system? These issues are analysed in this work.

The paper is organized as follows: Chapter 2 introduces the VOM under the view that management is a liberal art and proposes a VOM framework. Chapter 3 describes the evolution of the business process from the enterprise-centric to the network-centric models and highlights its importance as the kernel element of the proposed framework. In chapter 4 some questions on how to manage complexity in dynamic environments are addressed and some - possible - answers are provided. Finally, chapter 5 presents some conclusions as well as further questions that need to be addressed in the near future.

\section{MANAGEMENT: A LIBERAL ART}

In the research area, where consensus building is far from being an easy task, there is a man who came very close to overcome this obstacle: Peter Drucker - also 
known as the "Father of Management" - is perhaps the deepest and most recognized thinker the world has known in the field of management. His ability to question assumptions and see connections among disparate forces and data has made him a visionary man (Drucker, 1999).

Management, according to Drucker, is a liberal art. It is not a science though it deals in technology. It is not only a humanity even though it deals with people.

"Management is thus what tradition used to call a liberal art - 'liberal' because it deals with the fundamentals of knowledge, self-knowledge, wisdom, and leadership; 'art' because it is also concerned with practice and application. Managers draw on all the knowledge and insights of the humanities and the social sciences - on psychology and philosophy, on economics and history, on ethics - as well as the physical sciences. But they have to focus this knowledge on effectiveness and results... For these reasons, management will increasingly be the discipline and the practice through which the "humanities" will acquire recognition, impact, and relevance." (Drucker, 1989 and 2001)

This work explores the view of Peter Drucker that management is a liberal art and therefore the authors define VO Management (VOM) as:

The intentional act bound up with the intuitive attitude of running Distributed Business Processes (DBPs) and dealing with people by means of applying knowledge, skills and/or tools in order to allow organization and coordination of resources, monitoring of activities as well as adequate reaction whenever needed so that $\mathrm{VO}$ goals can be achieved.

This definition suggests that Dynamic VOM should rely on technological, socialorganizational and human enablers as well as on the existence of many different but complementary - management elements. Figure 1 presents one alternative for this VOM Framework where DBP Management is the kernel and the other management elements (such as Risk Management, Trust Management, Knowledge Management, and so forth) contribute to reinforce the management basis as well as the knowledge sharing and the decision making process.

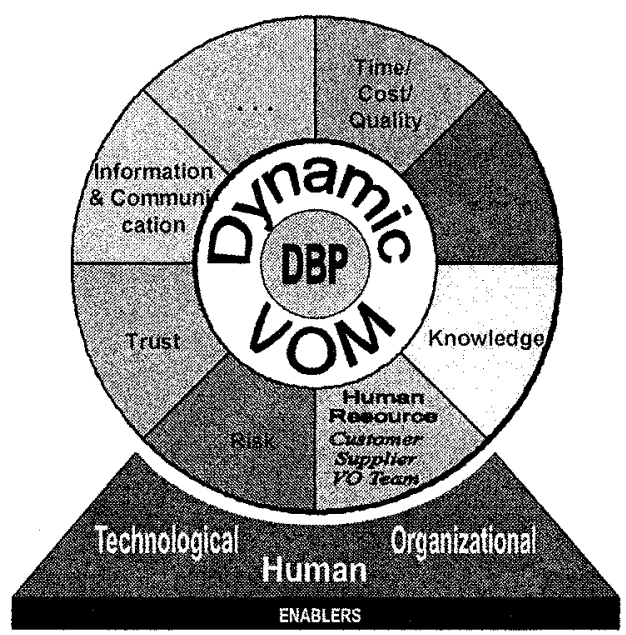

Figure 1: VOM Framework - a static vision of a dynamic framework 
The next chapter is devoted to the main VOM element: the DBP. For the other management elements presented in figure 1 the reader is referred to: Malhotra, 2000; Capó et al, 2004; Karolak, 1998; Geber et al, 2004; PMBOK, 2000.

\section{THE KERNEL ELEMENT}

When enterprises started to see the activities they carried out for accomplishing their final business goal as small "pieces of business" and understood that these "pieces" behaved like processes, then the history of the enterprises began to be written from the business processes point of view. The information associated to the enterprises' activities as well as their relationships started to be modeled in such a way that the business processes could be represented according to different visions (organizational, technical, functional, etc). This representation (modeling) should enable enterprises to better understand their business processes in order to facilitate and improve the global business being run. The business process (BP) concept started to be exploited from many perspectives: BP implementation, BP monitoring, $\mathrm{BP}$ analysis, $\mathrm{BP}$ re-engineering, $\mathrm{BP}$ management, and so forth. Over decades this is still a very fertile field.

When the attention of industrial and academic worlds started to be deviated with more intensity (something about ten to fifteen years ago) from the enterprise-centric to the network-centric models, the business process area also followed this trend (with a small time-gap). The BPs were no longer confined to the enterprise borders. One more vision started to be considered: the meta-vision. This vision should allow the understanding of the Meta-BP carried out by a network of enterprises (or any other kind of organizations) which came together for a certain period of time (short or long) to attend to a business opportunity. Some of the definitions that appeared to describe the Meta-BP (or associated perspectives) include:

- Distributed Business Process (DBP) is a dynamic and temporary set of business processes (BP) which jointly gives rise to the end product of the virtual enterprise (Spinosa et al, 1998; Pereira-Klen at al, 1999).

When a business process is executed by a virtual enterprise, parts of the decomposition of this BP (i.e., sub-processes) are assigned to different enterprises, becoming a Distributed Business Process (Camarinha-Matos, 2001).

- Distributed Business Process Management (DBPM) offers a new approach and allows organizations to link highly autonomous nodes, such as mobile users or partners, to a seamless process chain. This approach is ideal for manufacturing and supply chain related industries (BPE, 2004; Gensym Co., 2004).

- Collaborative Business Process Management (CBPM) addresses the weaknesses of current process logic models requires expanding the definition of process logic to include both explicit structured flows and the unstructured collaborative flows that characterize how people typically work. CBPM represents a new category of software that breaks down the barrier between the structured and unstructured world of collaboration and BPM. (O'Leonard, 2002). 
- Collaborative Process Manager (CPM) supports decentralized, peer-to-peer process management for inter-enterprise collaboration at the business process level. A collaborative process is not handled by a centralized workflow engine, but by multiple CPMs, each represents a player in the business process. Each CPM is used to schedule, dispatch and control the tasks of the process that the player is responsible for, and the CPMs interoperate through an inter-CPM messaging protocol (Chen et al).

- Federated Business Processes (FBP) are understood as a concept to organise contract-based co-operations between independent organisations, which support the exchange of information, products and services. One of the key advantages of the concept of federation is the hiding of the internal structure of the individual processes and their internal knowledge from the participating organisations as much as possible. Only those objects that are to be exchanged will be disclosed to the collaborators. This means partners still have the freedom to change and improve their processes without violating the co-operation agreements. But to interoperate across organisational boundaries, process interfaces have to be provided that enable the desired exchange (Wagner, 2004).

- Global Process Model (GPM) shows how a process model is distributed. It abstracts details of local process models (Gruhn et al, 1998).

There are several other related definitions that could be included here. The above examples are just to give a flavor of the BP "movement" towards the Collaborative Networked Organization world. In this paper the term that will be adopted for referring to the Meta-BP is: "Distributed Business Process" (DPB) since its definition is in line with the work that has being carried out by the authors during the last years.

The evolution of the DBP is being much faster than one could imagine thanks to the experience gained through the BP history. Although there is still a lack of theoretical foundations as well as consolidations in terms of ICT support for CNOs many efforts surrounding the DBP concept have been done and are moving well forward. In this sense, DBP modeling, DBP implementation, DPB management and others are already a consistent part - in spite of still being "under construction" - of the CNO framework. Researchers will continue their search for standards or, at least, for well-accepted references in the DBP field. This means that the VOM kernel is in good hands. But VOM is not only about managing DBPs. It is also about reacting adequately whenever needed as well as taking decisions.

The next chapter will address these topics and introduce some thoughts on the liberal art of managing dynamic VOs.

\section{SOME QUESTIONS AND - PROBABLY - SOME ANSWERS}

It is not a trivial task to model something that is considered a "liberal art". How to come out with a VOM Framework? Actually, it is rather difficult to represent something that is dynamic by its nature. In this sense we have to do with two big issues: Management is dynamic; and so do the VOs... At every turn, in the middle of this dynamicity sits the VO Manager who, by the way, has its own way of being. 
This means that different VO Managers imply different management styles (even if they rely on the same management elements and on the same enablers). So, if we take the VOM wheel represented in figure 1 and try to see it using the glasses of 3 different VO Managers we would probably get 3 different pictures (figure 2 middle). It is like looking to the VOM Framework using a Kaleidoscope eye. Every time you turn it you will get different pictures. These pictures represent the VO Manager behaviour or the VO Manager profile (figure 2 - bottom).

All these parameters should be taken into consideration for an adequate VOM. But in order to accomplish this some questions ${ }^{1}$ have to be addressed:

- How managers use skills and knowledge acquired in the liberal arts for the design and use of adaptive management systems also referred to as Management Coordination System (MCS)?

- How can the manager profiles and the management elements be combined and used?

- How do we connect all the involved parameters with "different ways on how to manage a VO"?

- Is there a way to define services (i.e. Web Services) and their allocation to specific VOM?

- Should (and if yes how) the services be coordinated or orchestrated in the categories?

- How to integrate the measurement systems that are necessary for communicating goals and objectives and for achieving alignment in adaptive organizations into the design of the MCS?

On the one hand it is clear that a broad range of skills is necessary to manage complexity in intense environments including technical, systems design, measurement, analytical and leadership skills (MGT 344, 2002). On the other hand the challenge remains: how to connect technology and performance measurement, including Internet technology, with knowledge of the humanities and social sciences acquired in the liberal arts?

This section intends to address the above raised questions and to provide some probably - answers which include the following considerations:

- There is no single/fixed VOM Framework. The VOM framework is fluid/dynamic;

- The DBP management is the kernel of the dynamic VOM framework;

- Management elements - others than DBP management - reinforce the VOM basis. However, there is no complete or correct list of management elements. The management elements can be "elected" (risk, trust, knowledge, and so forth) and combined according to the managers/developers knowledge and/or priorities;

- The development of a MCS set of functions/services for dynamic VOM should focus on management elements in general and on DBP management in particular; 


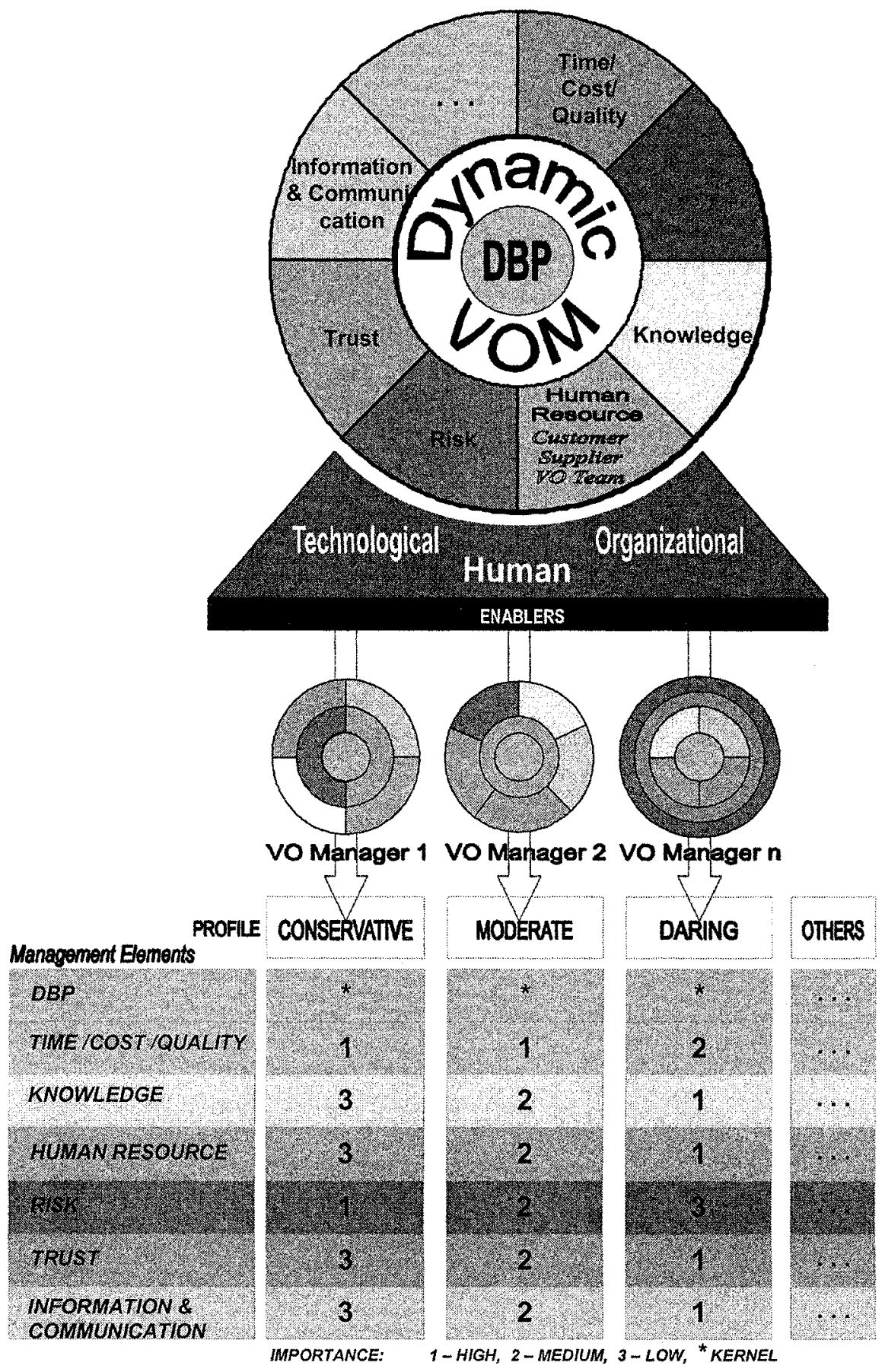

Figure 2: Dynamic VOM framework 
- The behaviours of the VO Managers can be mapped with the management elements. In figure 2 the colours as well as the concentric and surface weighting denote the importance of the management elements (high, medium, low) in and for specific VO Managers' profiles (for instance, a "conservative" profile implies that the manager considers the risk management of high importance);

- Weighting the management elements for each manager profile is an exercise that requires knowledge of process as well as of human behaviours and which must be improved / fine tuned along the long-life management process;

- The services provided by the MCS for VOM are classified into Classes: I and II;

- VOM services class I includes all functionalities that support DBP management (to allow organization and coordination of resources as well as supervision and monitoring of activities);

- VOM services class II includes all functionalities that support decisionmaking and adequate reaction whenever needed including dynamism on negotiation process with adaptive behaviour. Therefore class II is based on the remaining management elements.

For some functionalities of class I, the reader is asked to refer to (Pereira-Klen et al 2002; Rabelo et al, 2002 and 2004). For VOM services class II, 3 possible functionalities ${ }^{2}$ are described below:

Mining: "Torture the data till they confess..." The data/text/web bases have sometimes information "treasures". There is some valuable information that is hidden behind the enormous amount of data that are generated along the time. Data/Text/Web Mining allows the exploration and identification of relationships among variables that were originally independent. This potentiality combined with the Business Intelligence paradigm will allow to filter a great amount of data/text stored in the repositories, to establish relations among them as well as to organize and to transform them into useful information. This information, combined with some benchmarking techniques and with an ontology-based standardization, will form a knowledge base which in turn will support managers to take faster and at the same time smarter decisions.

Knowledge Map: The main idea behind this functionality is to take the most advantage possible of the VO cross-functional team. This means that the VO manager would not "just" manage the VO but would also manage knowledge. The VO members need to learn from their experience in a dynamic constellation as well as from the creativity and the intellectual capital from their organizations and from the individuals involved (the humanistic part of the management...). This knowledge which crosses boundaries may create a competitive advantage for the enterprises and may be a market asset for this new working environment. Different and complementary "kinds" of knowledge should be considered: knowledge of clients, of products, of processes, of relations and of businesses (Spinosa, Quandt, 2000). In this sense, all this knowledge extracted from the Knowledge Map should also be added to the knowledge base. 
Negotiation (Fuzzy management): This functionality should support the fuzzy management (Filos, 2000) of the Dynamic VOs, acting in the negotiation process as well as helping the VO reconfiguration and in an eventual modification in the DBP contract. Therefore this functionality relies on the two previous ones.

There are many ways to proceed in a negotiation process until an agreement is reached. They are usually made by means of relaxation of some values specified in an "announcement", such as those related with the product tolerance, due date, prices, etc. This functionality should provide the manager with an environment to support an electronic and/or semi-automatic negotiation heavily relying on the knowledge base, on machine learning techniques as well as on DSS (Decision Support Systems) theories.

It is important to note that the knowledge base will encompass knowledge about the management elements (risk, trust, human resource, ICT, and so forth). This means that learning algorithms will be applied to the knowledge base and will be responsible for the 'intelligent processes' on the system suggesting actions to the VO manager (Loss et al, 2005). The possible solutions are given according to the characteristics of the problem and can be ranked by the managers (all managers that had faced similar problems) according to their own profiles. This means that the system will propose possible solutions and will link them with the managers' behaviours and their related efficiency coefficient.

The big deal is to create a reliable knowledge base and to feed it with VOM knowledge. Best practices, benchmarking, and adopted approaches in the VOM area are very few. The way to come out of this handicap seems to be to create a pilot knowledge base in which the experience of researchers will play the most important role. After that, like as for the weighting of the management elements, the knowledge base must be improved and fine tuned along its long-life process.

\section{CONCLUSIONS AND NEXT STEPS}

The work presented in this paper reflects in part the DBP maturation process, its close and direct relation to the VOM's sustained improvement as well as the awareness that has to be raised around this natural evolution stage. Functionalities to support DBP management - in this paper named as VOM services class I - were already identified, modeled, conceived and - in some cases - developed within the scope of some research projects (PRODNET II, 1999; Damascos, 2001; MyFashion, 2004). However functionalities to support the whole VOM framework and its dynamicity - VOM services class II - are missing.

The authors believe that a human-supervised VOM system can include the socalled class II functionalities which will grant to the system a personalized flavour. It is expected that this research path crosses in sometime not very far the path of the Ambient Intelligence vision (Pereira-Klen et al, 2005). But before that some further questions have to be addressed. Out of them two are of immediate priority: how can we bring in and integrate to this personalized VOM system the performance indicators? And, while waiting for the ambient intelligence space, how will we train VO Managers in the liberal art of managing VOs? 


\section{Acknowledgments}

This work was supported in part by the IST FP-6 IP ECOLEAD project (www.ecolead.org) funded by the European Commission as well as by the IFM project (www.ifm.org.br) funded by the Brazilian Council for Research and Scientific Development - CNPq.

${ }^{1}$ Questions raised by the ECOLEAD WP3 team as well as by the course: "Adaptive Management Systems: Management as a Liberal Art"- MGT 344, held at the Drucker School of Management Claremont Graduate University - Spring 2002

${ }^{2}$ These functionalities, identified in recent research projects according to end-users' requirements, are under development and should improve the Cockpit prototype developed by UFSC. The currently available functionalities of the prototype allow the managing of DBPs of Virtual Organizations by means of monitoring and supervision activities.

\section{REFERENCES}

1. BPE - Business Process Excellence. Web page: http://www.ids-scheer.com/usa/press/26175 - accessed in July, 19, 2004.

2. Camarinha-Matos, L. M.; Afsarmanesh, H.; Kaletas, E. C. ; Cardoso, T.; Service Federation in Virtual Organizations. In Proceedings of The Eleventh International IFIP TC5 WG-5.2-WG-5.3 Conference (PROLAMAT 2001), 2001.

3. Camarinha-Matos, L. M.; Execution system for distributed business processes in a virtual enterprise. In: Future Generation Computer Systems 17 (2001) 1009-1021

4. Capó, J, Masiá E, Lario FC. "Inter-Organizational Knowledge Management. The Importance of Organizational and Environmental Context". Book: Virtual Enterprises and Collaborative Networks. ISBN 1-4020-8138-3, Kluver Academic Publishers, 2004.

5. Chen, Q.; Hsu, M.; Inter-Enterprise Collaborative Business Process Management. HP Labs, Hewlett Packard Co. gchen@hpl.hp.com

6. Damascos, 2001. http://www.inescporto.pt/ damascos/

7. Drucker, Peter. Management Challenges for the $21^{\text {st }}$ Century, Harper Business, 1999.

8. Drucker, Peter. The Essential Drucker. HarperCollins, ISBN: 0066210879, 2001.

9. Drucker, Peter. The New Realities. Harper \& Row, 1989, p. 231

10. Filos E.; Banahan E. "Will the Organisation disappear? The Challenges of the New Economy and Future Perspectives". Book: E-Business and Virtual Enterprises, Kluver Academic Publishers, 2000.

11. Geber A, Althaus K, Dietzsch M, Weidlich D, Steiner R. "Risk-Management of Product Development in Non-Hierarchical Regional Production Networks". Book: Virtual Enterprises and Collaborative Networks. ISBN 1-4020-8138-3, Kluver Academic Publishers, 2004.

12. Gensym Corporation and WebV2 Join Forces to Offer Rule-Intensive Solutions for Distributed Business Process Management. Web page: http://www.webv2.com/pr/040414 Gensym.html accessed in July, 19, 2004.

13. Gruhn, V.; Wellen, U.; From Business Process Models to Distributed Software Architecture. In Proceedings of the third International Workshop on Software Architecture, pages 53--56, 1998.

14. Guide to Business and Information Modeling for the Development of Edifice Implementation Kits. htto//www.edifice.org/REP/bigguide.pdf

15. Karolak, DW. "Global Software Development - Managing Virtual Teams and Environments". Los Alamitos, IEEE Computer Society, 1998

16. Loss, L.; Rabelo, R.; Pereira-Klen, A.A., 2005, For an Intelligent Decision Support System for Supply Chain Management. To appear in CIRP 2005 Conference. May, 2005 - Florianopolis, Brazil.

17. Malhotra, Yogesh. "Knowledge Management and New Organizations Forms: A Framework for Business Model Innovation". Book: Knowledge Management and Virtual Organizations. ISBN 1878289-73-X, Idea Group Publishing, 2000.

18. MGT 344. Drucker School of Management - Claremont Graduate University - Spring 2002. 
19. MyFashion, 2004. http:/www.myfashion.org/ and/or http://www.fir.rwthaachen.de/projektseiten/myfashion/

20. O'Leonard, J.; Business Process Logic: Half Empty or Half Full? December 02, 2002. http://www.bijonline.com/Article.asp?ArticleID $=629$ \&DepartmentID $=7$

21. Pereira-Klen, A. A.; Klen, E. R.; Loss, L. 2005. Challenging Scenario: Dynamic Supply Chains Supported by Ambient Intelligence System. To appear in CIRP 2005 Conference. May, 2005 Florianopolis, Brazil.

22. Pereira-Klen, A. A.; Rabelo, R. J.; 2002. Business Intelligence Support for Supply Chain Management. In: Balanced Automations Systems in Manufacturing and Services (BASYS'02). Knowledge and Technology Integration in Production and Services. (Sep. 25-27,2002: Cancun, Mexico). Proceedings, p. 437-444.

23. Pereira-Klen, A. A.; Rabelo, R. J.; Spinosa, L. M.; Ferreira, A. C.; Distributed Business Process Management. In: working Conference on Infrastructures for Virtual Enterprises (PRO'VE 99). Infrastructures for Virtual Enterprises. Networking Industrial Enterprises (27-28.: Oct. 1999: Porto, Portugal). Proceedings. Porto, Portugal. p. 241-258.

24. PMBOK, 2000, - A Guide to the Project Management Body of Knowledge (PMBOK Guide). Project Management Institute. Four Campus Boulevard. Newton Square, USA.

25. Prodnet II, 1999. http://www.uninova.pt/ prodnet/

26. Rabelo, R. J.; Pereira-Klen, A. A.; Klen, E. R.; 2002. A Multi-Agent System for Smart Coordination of Dynamic Supply Chains. In: Infrastructures for Virtual Enterprises (PRO-VE'02). Collaborative Business Ecosystems and Virtual Enterprises. (May 1-3. 2002: Sesimbra, Portugal). Proceedings, p. 379-386.

27. Rabelo, R. J.; Pereira-Klen, A. A.; Klen, E. R.; 2004. Effective Management of Dynamic and Multiple Supply Chains. In: International Journal of Networking and Virtual Organizations. Vol. 2. n. 3. p. 193-208.

28. Spinosa, L. M.; Rabelo, R. J.; Pereira-Klen, A. A.; High-Level Coordination of Business Processes in a Virtual Enterprise. Prolamat'98 / The Tenth International IFIP TC5 WG-5.2 WG-5.3 Conference Trento, Itália

29. Spinosa LM. Quandt C. "An IT-based framework for Knowledge Management in Networked Organizations". Book: E-Business and Virtual Enterprises, Kluver Academic Publishers, 2000.

30. The ebXML Collaborative Business Processes. Web Page: http:/www.schlegel.li/ebXML/inmagau article/www/node6.htm1

31. Wagner, K. Schwarzenbacher. Föderative Unternehmensprozesse - Technologien, Standards und Perspektiven für vernetzte Systeme (Federated Business Processes - Technologies, Standards and Perspectives of Network Systems), (in German), Siemens, Publicis Corporate Publishing, Erlangen, 2004, ISBN 3-89578-231-9 